DOI https://doi.org/10.32405/2218-7650-7(36)-9-21

УДК 373.018:659

\title{
Анна Вишневска,
}

Учебно-научен институт по управление и психология, Държавен университет

«Университет по мениджмънт образование»,

Киев, Украйна.

Научен ръководител - Г. М. Тимошко

ozdoba@i.ua

\section{МЕТОД И ОПИТ НА МАЙСТОРСКИЯ КЛАС}

Анотация. Принцип на майсторския клас: «Знам как да го направя, ще те науча».

Майсторският клас е една от формите на ефективно професионално, активно учене. Тя се различава от семинара от факта, че по време на майсторския клас водещ специалист (наричан по-нататък учителят) разказва и, по-важното, показва как да се приложи на практика нова технология или метод.

По време на майсторския клас учителят представя своя собствена система на работа, която включва набор от методични техники, които са присъщи на този учител. Действията на учителя са взаимосвързани, оригинални и осигуряват ефективно решение на задачите. Признаците на системата за работа на учителя са целостта, оптималността при определяне на мястото и времето на всяка методологическа употреба, гъвкавостта на влиянието върху слушателите, оригиналността на метода. Майсторският клас осигурява формирането на мотивационните и познавателните потребности на учениците в определена дейност; стимулира познавателния интерес. В хода на майсторския клас се развиват умения за планиране, самоорганизация и самоконтрол на педагогическите дейности. По време на майсторския клас се взема индивидуален подход по отношение на всеки ученик и се наблюдават положителните резултати от образователната дейност. Майсторски клас е форма на организация на активната самостоятелна работа на слушатели, при която се използват емпирични методи на изследване: наблюдение, изучаване на документи и резултати от дейността, тестване, разработване на дидактични материали за експериментална и експериментална работа в собствена педагогическа дейност.

Ключови думи: майстор; система; оптималност; прием; оригиналност. 


\section{1. ВЪВЕДЕНИЕ / ВСТУП / INTRODUСТION}

Изявление на проблема. На сегашния етап на развитие на образованието, идентифицирането, обобщаването и разпространението на иновативния педагогически опит става от значение. Един от най-ефективните начини за разпространение на собствения си педагогически опит е една съвременна форма на методологическа работа като майсторски клас.

Тази концепция е широко използвана в много сфери на човешката дейност, включително в образованието. Най-често в педагогическата общност под майсторски клас те разбират урока, събитието, представянето на постиженията на учителя, но това не е така.

В педагогическата литература има десетки определения на понятието «майсторски клас». В този случай се използва дефиниция, където се маркират ключовите свойства на майсторския клас.

На първо място, майсторският клас е отворена педагогическа система, която ви позволява да демонстрирате новите възможности на педагогиката на развитието и свободата, която показва начини за преодоляване на консерватизма и рутината.

Майсторски клас е специален жанр на обобщаване и разпространение на педагогическия опит, който е фундаментално разработен оригинален метод или авторска техника, базирана на нейните принципи и има определена структура. От тази гледна точка семинарът се различава от другите форми на превода на опита чрез факта, че в хода на неговото провеждане се провежда директно обсъждане на предлагания методологически продукт и търсенето на творческо решение на педагогическия проблем както от участниците в майсторския клас, така и от учителя, който ръководи този учител-клас.

Тази форма на методологическа работа е ефективен начин за прехвърляне на опита от обучението и образованието, тъй като централната точка е демонстрирането на оригиналните методи за овладяване на определено съдържание за активната роля на всички участници в класа.

Следователно, майсторският клас е форма на заетост, в която са концентрирани следните характеристики:

- Предизвикателство към традиционната педагогика;

- Личността на учителя с ново мислене;

- Не пасивно придобиване на нови знания, а начин за самостоятелното им конструиране с помощта на всички участници в класа.

Обобщавайки горното, можем да разграничим най-важните характеристики на майсторския клас, а именно:

- Нов подход към философията на обучението, който нарушава установените стереотипи. 
- Метод за самостоятелна работа в малки групи, който позволява обмен на мнения.

- Създаване на условия за участие на всички в активни дейности.

- Създаване на проблемна задача и решаването му чрез разглеждане на различни ситуации.

- Приеми, които разкриват творческия потенциал като учител, провеждат майсторски клас и неговите участници.

- Предлагат се форми, методи, технологии на работа, но не са наложени на участниците.

- Процесът на познание е много по-важен, по-ценен от самото познание.

- Форма на взаимодействие - сътрудничество, съвместно създаване, съвместно търсене.

При подготовката на майсторски клас трябва да се обърне внимание на факта, че най-важното в технологията на неговото изпълнение - не да информира и да овладее информацията, а да прехвърли начините на дейност, независимо дали това е прием, метод, методология или технология. Предаването на продуктивни начини на работа е една от най-важните задачи за учител, който провежда майсторски клас. Положителният резултат от семинара е резултатът, изразен в овладяване на участниците чрез нови творчески начини за решаване на педагогическия проблем, при формиране на мотивацията за самообразование, самоусъвършенстване, саморазвитие. Това е технологично сложен процес с определени изисквания за неговата организация и поведение.

Майсторски клас като местна технология за транслиране на педагогическия опит, демонстрира специфичен методологичен метод или метод, методика на преподаване, технология на обучението и възпитанието. Тя трябва да се състои от задачи, които насочват дейностите на участниците за решаване на поставения педагогически проблем, но в рамките на всяка задача участниците са напълно свободни: трябва да направят избор на начин на изследване, избор на средства за постигане на целта, избор на темп на работа.

Майсторският клас трябва винаги да започва с актуализиране на знанията за всеки според предложената задача, което ще позволи да се разширят техните представителства със знанията на другите участници.

В технологията на провеждане на майсторски клас се използва определен алгоритъм за решаване на педагогически проблем. Алгоритъмът е формализиране на технологичния процес под формата на поредица от няколко стъпки, блокове на дейност, които зависят от съдържанието на 
педагогическия проблем, но имат обща педагогическа част, която се определя от общите режими на дейност.

Анализ на последните изследвания и публикации. Този въпрос е предмет на изследване от много учени. Провеждането на такива събития като майсторски клас е неразделна част от образа на учебното заведение, което от своя страна допринася за развитието на творческия потенциал на преподавателския състав на учебното заведение. Този брой се изучава предимно в областта на общото средно образование В. Бондар, Л. Ващенко, Б. Гершунски, Г. Дмитренко, Ю. Конаржевски, Н. Лукашевич, В. Маслов, В. Огневик, М. Поташник, В. Пехленой, А. Подласим, А. Попов, А. Савченко, Г. Атаманчук, В. Афанасиев, Д. Бел, М. Вебер, Г. Моска, Т. Парсънс, В. Парето, Й. Тихомиров, А. Черниш. Вниманието на учените се набляга на специалисти с изразени способности за професионално педагогическо творчество, което се характеризира с ново педагогическо мислене, чиято ценностна ориентация е превъзходството на творческата индивидуалност над единодушието (И. Зязун, Ф. Хоноболин, В.Загвязински, Н. Кузмин, М. Лещенко, В. Семиченко и др.), Самоусъвършенстване, самоусъвършенстване, самореализация - над единни условия за «прехвърляне» на знания (А. Богуш, Г. Бал, И. Зязун, Н. Кичук, Н. Ничкало, О. Орлов, О.Пехот, М.Сергеев, С.Сисоев и др.). Анализът на психологопедагогическите изследвания на този проблем предполага, че успехът на този процес зависи от формирането на компетентност като един-единствен магистър, а педагогическата креативност на персонала на учебното заведение се изучава в следните основни направления:

- обосновка на общите основи на педагогическото управление (Л. Даниленко, Г. Елникова, В. Маслов, В. Олийник, В.Пикелна, А. Йермола, Л. Карамушка, Й. Конаржевски, О. Мармаз и др.);

- разкриване на спецификата на административната дейност на администрацията на учебното заведение (С. Боруч, Л. Василченко, В. Гладков, И. Драч, И. Жерносек, Г. Елникова, Л. Калинина, М. Кириченко, С. Королюк, В. Крижко, М. Лапшина, В. Маслов, В. Мелник, П. Милютин, Н. Островерхова, Е. Павлюшенков, С. Рябова, Т. Сорочан, Г. Тимошко, Л. Туришева и др.).

Разглеждайки институцията като цялостна система, изследователите смятат, че нейните оптимални средства за препитание са възможни само със способността на мениджъра да планира, организира, регулира, контролира и диагностицира работата на екипа на научна основа.

\section{2. ЦЕЛТА И ПРОБЛЕМ / МЕТА ТА ЗАВДАННЯ / AIM AND TASKS}

Целта на статията. Да покаже водещата роля на учителя-майстор, който да работи на настоящото ниво, непрекъснато да подобрява, развива и 
обогатява своята професионална компетентност, иновативна култура, технологичен потенциал, представяйки опита на работата по проблема на майсторския клас и показвайки ефективността на работата по този проблем, насърчаване на увеличаването професионалната компетентност на учителите, самообучението и развитието на комуникативни умения и методически умения.

\section{3. ТЕОРЕТИЧНИ ОСНОВИ НА ИЗСЛЕДВАНИЯТА / ТЕОРЕТИЧНІ ОСНОВИ ДОСЛІДЖЕННЯ / THЕ THЕОRЕTICAL BACKGROUNDS}

Представяне на основния материал. Овладяването на формата на обучение, което придобива все по-голяма популярност в настоящето, е оправдана мярка за иновативен подход за реализиране на активно и професионално обучение в почти всяка сфера на човешката дейност.

Манипулирането на термина «майсторски клас» понякога се заменя с формата на практически упражнения за укрепване на теоретичния материал или няколко дни на овладяване на първоначалните основи на нововъзникналите предпочитания на дадено общество.

Въз основа на тази позиция е възможно да се разглежда всякакъв вид дейност в детска градина или основно училище като майсторски клас. И тази идея може да има право да съществува, но все пак е невярна, защото майсторският клас предполага студент да има някакъв предишен опит, умения и способности, и най-важното, студентът е някак познат в теорията на предмета на майсторския клас.

\section{4. ИЗСЛЕДОВАТЕЛСКИ МЕТОДИ / МЕТОДИ ДОСЛІДЖЕННЯ / RESEARCH METHODS}

Майсторският клас може да бъде сравнен със спортни тренировки, където треньорът вече е заслужен спортист, който на свой собствен пример и атлетични упражнения учи и обучава своите ученици - също спортисти, още не шампиони, но не и начинаещи.

\section{5. РЕЗУЛТАТИТЕ ОТ ИЗСЛЕДВАНИЯТА / РЕЗУЛЬТАТИ ДОСЛІДЖЕННЯ / RESEARCH RESULTS}

Главното отличие на майсторския клас от класическите и традиционните разновидности на обучението: уроци, лекции, семинари, практически упражнения и др. лична практическа реализация на собствените си умения, умения и знания, придобити от него, докато самият Учител показва на собствените си упражнения или технологии как да приложат тези знания и умения. 
Това означава, че Учителят: казва, показва, предлага самостоятелна работа, наблюдава и коригира, учи; Ученици: слушайте, виждайте, изпълнявайте индивидуална работа, поправяйте грешките си, научете се или увеличете нивото си. Комбинацията от теоретични насоки с тяхната творческа реализация на практика, използване на нови технологии и техники, със съвместното участие на Учителя и Студента, е най-ефективната и ефективна форма на обучение, както на класическите знания, технологии и техники, така и на избираеми, нови и иновативни.

Необходимо е да се съсредоточи вниманието върху тежката част от майсторския клас - творчеството. Творческият подход в майсторския клас трябва да се отнася до:

- комуникация със студентите - установяване на контакт и внимание;

- подаване на информация на учениците - възприемане на информация чрез контакт;

- създаване на «обратна връзка» със студентите - предизвикване на предложения, собствени идеи и др.

Exercises практически упражнения - идентифициране на индивидуалното виждане на ученика и неговия собствен стил, откриването на нови идеи или техники за технологично изпълнение на задачата.

Разбира се, творчеството е по-лесно да се реализира в областите, в които присъства в съдържанието: музика, изкуство, литература, архитектура, дизайн и т.н., и накрая - педагогика.

Но дори и в неизменната физика или математика, творческите идеи доведоха до откриването на нови закони. Така че, просто трябва само да искате.

Отличителна черта на майсторския клас е времето, посветено на неговото провеждане. Обикновено това време се изчислява за десетки минути и не повече от няколко часа. Това означава, че майсторският клас изисква достатъчно време само за практическото изпълнение на определени действия, за да се постигне разкриването на дадената тема.

Превишаване на оптималното време, уморен от Студент, релаксиращ Учител, загуба на енергийна концентрация, внимание и търпение майсторският клас става академичен урок, или още по-лошо, на курс за обучение с последващи проучвания и практически задачи, за които рейтингът е в дневник.

Целта на майсторския клас е да подчертае определена тема, традиционни и извънредни технологии за практическата реализация на задачите на предмета, авторските идеи и техники, идентифицирането на възможни иновативни технологии или методи чрез съвместната творческа дейност на Учителя и Ученика. 
Разбира се, има изключения от правилата и условията за организиране и провеждане на майсторски клас. В такива случаи спецификата на темата или липсата на опит у ученика и др. Не се превръща в пречка за творческото сътрудничество на Учителя и Ученика. Такъв творчески подход, в майсторския клас, може да разкрие скрити способности дори в неподготвения ученик.

Разбира се, има изключения от правилата и условията за организиране и провеждане на майсторски клас. В такива случаи спецификата на темата или липсата на опит у ученика и др. Не се превръща в пречка за творческото сътрудничество на Учителя и Ученика. Такъв творчески подход, в майсторския клас, може да разкрие скрити способности дори в неподготвения ученик.

Ето защо, трябва да се разбира, че в повечето случаи, само при наличие на комбинация от определени условия и съответствието на тези условия със задачата на майсторския клас, такъв процес на обучение може да бъде ефективен и продуктивен.

Такива задачи на майсторския клас могат и трябва да бъдат:

- комбинация от теоретично и практическо обучение чрез съвместна творческа работа по изпълнението на тематичната задача;

- предоставяне на определени знания и информация от Учителя на ученика; техники;

- демонстриране на последователността от действия, методи и

- коментар и корекции в процеса на изпълнение на задачата;

- усвояване на новия професионален опит за самоусъвършенстване на техните умения;

- получаване на изключителна информация;

- възприемане на нови и алтернативни методи и техники;

- самоизпълнение на задачата под надзора на Учителя;

- получавате удоволствие от собственото си постижение.

В съвременната практика за организиране и провеждане на майсторски клас, няма изчерпателни списъци на последователността на действията на Учителя или правилата за поведение на ученика в процеса на майсторския клас. Всеки Учител има своите проявления на личността в такъв процес, всеки третира процеса по свой собствен начин, всеки има свои собствени «бисквитни» тайни.

Ето защо провеждането на майсторски клас може да се проведе във всякаква форма, без никакви планове и норми. Всичко зависи от Учителя и Ученика. Трябва да се отбележи обаче, че процесът на майсторския клас, 
дори и на всяка тема, съдържа скрити педагогически и психологически техники и методи, които го правят управляем, според неписания алгоритъм.

Препоръчително е Учителят да развие личния си път в тази посока, което ще гарантира успех както за него, така и за ученика. По-долу е представен приблизителен алгоритъм на главния клас.

За опростяване на подготовката, организацията и провеждането на майсторския клас се предлага единен алгоритъм за реализация на майсторския клас.

1. Организационна част.

1) Определяне на темите на майсторския клас;

2) определяне на състава, броя на студентите, условията и мястото на провеждане;

3) подготовка на тематични материали (инструменти, суровини, оборудване, литература, образци и др.) в съответствие с условията на провеждане.

2. Основната част.

1) Представяне от Учителя:

- характеристика на професионалната дейност;

- постижения и различия на собствен опит, умения и способности;

- сравнение с други технологии;

- проблеми, перспективи, прогнози.

2) Представяне на темата (задача) - теория:

- информиране за съдържанието на тематичната задача;

- представяне на тематична извадка (продукт, модел и др.);

- събития (технология) на изпълнение на задачата;

- основни задачи на задачата и тематични материали.

3) Обучение - семинар:

- демонстрация на определени техники за слушателите;

- независими резултати от слушателите на тези техники;

- съвместна оценка на резултатите;

- прилагане на коригиращи действия.

4) Симулация - работна среща:

- самостоятелна работа на учениците (индивидуално или работа в група) върху технологиите и техниките на Учителя;

- надзор на Учителя за самостоятелна работа, консултиране, коригиращи действия.

3. Последната част.

- Индивидуално представяне на самостоятелна работа от слушателите;

- оценка на работата; 
- обсъждане на резултатите от майсторския клас.

Спазването на всички компоненти на предложения алгоритъм ще насърчи възможно най-доброто провеждане на майсторския клас: рационализира разходите за ресурси, спестява време и създава творчески диалог-атмосфера между Учителя и Ученика.

Така майсторският клас е една от най-добрите форми на практическо самоусъвършенстване на определено ниво на умение на всеки ученик. Авторската система и блиц-работният план Учител, желание и любопитство Ученикът да научи нещо ново, което да повиши професионалното си ниво, може да създаде всички условия за ефективен творчески тандем - студентмайстор.

Като примери за провеждане на майсторски класове могат да се цитират събития, които се провеждат с участието на автора.

Освен ежедневната работа в детска градина, за междинна или окончателна оценка на творческата активност на учениците и положителната им емоционална стимулация периодично се организират майсторски класове по декоративно изкуство. В такива дейности могат да участват специалисти (служители на институцията), които имат разнообразни изкуства и споделят своя опит и умения с ученици от различни области на детското изкуство.

Като правило колеги от други детски институции, родители и роднини на ученици, както и техните приятели, са поканени на такива майсторски класове. Учениците могат да демонстрират уменията си за креативност, повтаряне, а понякога и подобряване на артистичните и технологични техники на майсторите. Начинаещи гости - откриване на свят на творчески възможности, наслаждават се на естетическата работа, която подсказва много преди първите опити на собствените си възможности в такова изкуство.

Характерна особеност на тези майсторски класове е, че възрастовата бариера между Учителя и Учениците или между зрителите и Учителя изчезва от началото на действието. Всички те поглъщат творческата страст, общуването и съвместната работа, което насърчава по-доброто разбиране на ученията на Учителя от инструкторите. В резултат на това всяко завършено творчество - композиция, е перфектно в възприемането не само на Ученика, но и на Учителя.

Учителят не ограничава студентите до тяхната визия, опит, техники или умения. За да разкрие хоризонтите на творчеството на всяка възраст, Учителят препоръчва студентите периодично да участват в майсторски класове в други области и други майстори. Не може да има граници на опита 
и подобренията, поради което цялостното развитие на студентите допринася за техния артистичен растеж.

За известно укрепване на уменията и способностите на учениците, Съветникът насърчава децата да участват в различни изложби и детски състезания извън центъра. Такова участие е възможност да се запознаят студентите с техните първоначални артистични умения на ниво районни, градски и държавни събития за деца, младежи и младежи, което в бъдеще дава възможност на студентите за самостоятелна творческа дейност.

В същото време, магистърската необходимост да прехвърли своите знания, умения и опит е удовлетворена от новите майсторски класове, които Учителят провежда в общообразователни училища, детски клубове, изложби, панаири и др.

Учителят обаче се нуждае от ежедневно развитие на придобитите знания и опит, овладяване на нови методи, техники, нови художествени тенденции и технологии. Ето защо Учител периодично се превръща в студент в майсторските класове на други майстори. По този начин, съкровищница на Учителя се напълнява с днешното признато майсторство в декоративните изкуства, в повечето стилове и разновидности на флористиката, декорацията и дизайна.

\section{6. ЗАКЛЮЧЕНИЯ И ПЕРСПЕКТИВИ ЗА ПО-НАТАТЫШНИ ИЗСЛЕДВАНИЯ / ВИСНОВКИ ТА ПЕРСПЕКТИВИ ПОДАЛЬШИХ ДОСЛІДЖЕНЬ / CONCLUSIONS AND PROSPECTS FOR FURTHER RESEARCH}

По този начин Учителят разкрива пред слушателите системата на автора. Майсторският клас създава условия за нарастване на педагогическите умения в основа на отражението на собствения им педагогически опит. Постигането на целите в работата на майсторския клас се определя в съответствие с целта. Резултатът от съвместната дейност е модел на професия, дейност или друг продукт, разработен от Слушателя под ръководството на Учителя, за да използва този модел в практиката на собствената си дейност.

Като се има предвид гореизложеното и от собствения опит на автора, може да се убеди, че популярната форма на активно, творческо и професионално обучение в настоящата форма или придобиването на практически опит не е недостижима за обикновения специалист във всяка област. Заинтересованото и творческо отношение към усвояването на практиката на майсторските класове е гаранция за постигане на ефективни резултати както за самите майстори, така и за техните ученици. Поради тези особености на методологията на провеждане на майсторски клас, тя трябва 
да бъде популяризирана и въведена като иновация в учебния процес и в развитието на умения в различни области.

\section{7. СПИСЪК НА ИЗПОЛЗВАНИТЕ ИЗТОЧНИЦИ / СПИСОК ВИКОРИСТАНИХ ДЖЕРЕЛ / REFERENCES (TRANSLATED AND TRANSLITERATED)}

[1] І. П. Жерносек, Науково-методична робота в загальноосвітній школі. Київ, Україна: ІЗМН, 1998. 121 с.

[2] Майстер-клас в системі методичної роботи з педагогічними кадрами / А. І. Постельняк. Кіровоград, Україна: Видав. КОІППО ім. Василя Сухомлинського, 2009. 68 с.

[3] Е. В. Нечитайлова, «Технология мастер-класса в системе совершенствования педагогического мастерства учителя». Советы учителю. Ростов-на-Дону, Россия, № 11, 39 с., 2003.

[4] Г. А. Русских, «Практическое использование методики мастер-класса в работе учителя наук естественного цикла». Народное образование», № 3, 2001.

[5] В. Андрущенко, І. Табачек, «Формування особистості вчителя в сучасних умовах». Політичний менеджмент, № 1(10), с. 58-69, 2005.

[6] Г. К. Селевко, Альтернативні педагогічні технології. Москва, Россия: НДІ шкільних технологій, 2005, 224 с.

[7] О. Пометун, Л. Пироженко, Сучасний урок. Київ, Україна: А.С.К., 2005.

[8] В. В. Григораш, Педагогічні ради, майстер-класи, тренінги. Харків, Україна: Основа, 2013. 224 с. (Серія «Абетка керівника»).

\section{МЕТОДИКА ТА ДОСВІД ПРОВЕДЕННЯ МАЙСТЕР-КЛАСІВ}

\section{Вишневська Ганна Петрівна,}

завідувач відділення підготовки іноземних громадян до вступу у

вищі навчальні заклади Навчально-наукового інституту

менеджменту та психології

ДВНЗ «Університет менеджменту освіти»,

Київ, Україна.

Науковий керівник - Г. М. Тимошко

email:ozdoba@i.ua

Анотація. Принцип майстер-класу: «Я знаю, як це зробити, я вас навчу».

Майстер-клас $є$ однією з форм ефективного активного навчання. Він відрізняється від семінару тим, що на майстер-класі провідний спеціаліст (далі - викладач) розповідає й показує, як застосувати на практиці нову технологію або метод. 
Під час майстер-класу вчитель представляє власну систему роботи, яка має набір методичних прийомів, властивих цьому вчителеві. Дії вчителя взаємопов'язані, оригінальні, що забезпечує ефективне виконання поставлених завдань. Ознаками системи роботи вчителя $\epsilon$ цілісність, оптимальність щодо визначення місця і часу кожного методичного використання, оригінальність методу. Майстер-клас забезпечує формування мотиваційних і пізнавальних потреб учнів у певному виді діяльності, стимулює пізнавальний інтерес. У процесі майстер-класів розвиваються навички планування, самоорганізації і самоконтролю педагогічної діяльності. Під час майстер-класу до кожного учня застосовується індивідуальний підхід, завдяки чому спостерігаються позитивні результати навчальної діяльності. Майстер-клас - це форма організації власної роботи активних слухачів 3 використанням емпіричних методів навчання: спостереження, вивчення документів і результатів, тестування, розроблення дидактичних матеріалів для експериментальної роботи у своїй педагогічній діяльності.

Ключові слова: майстер; система; оптимальність; прийняття; оригінальність.

\section{МЕТОДИКА И ОПЫТ ПРОВЕДЕНИЯ МАСТЕР-КЛАССОВ}

\section{Вишневская Анна Петровна,}

заведующая отделением подготовки иностранных граждан

к поступлению в высшие учебные заведения

Учебно-научного института менеджмента и психологии

ГВУЗ «Университет менеджмента образования»,

Киев, Украина.

Научный руководитель - А. Н. Тимошко

ozdoba@i.ua

Аннотация. Принцип мастер-класса: «Я знаю, как это сделать, я вас научу».

Мастер-класс - одна из форм эффективного активного обучения. Он отличается от семинара тем, что на мастер-классе ведущий специалист (далее - преподаватель) рассказывает и показывает, как применить на практике новую технологию или метод.

Во время мастер-класса учитель представляет собственную систему работы, которая включает набор методических приемов, присущих этому учителю. Действия учителя взаимосвязаны, оригинальны, что обеспечивает эффективное выполнение поставленных заданий. Признаками системы работы учителя являются целостность, 
оптимальность в определении места и времени каждого методического использования, оригинальность метода. Мастер-класс обеспечивает формирование мотивационных и познавательных потребностей учащихся в определенном виде деятельности, стимулирует познавательный интерес. В ходе мастер-классов развиваются навыки планирования, самоорганизации и самоконтроля педагогической деятельности. Во время мастер-класса к каждому ученику применяется индивидуальный подход, благодаря чему наблюдаются положительные результаты учебной деятельности. Мастер-класс - это форма организации собственной работы активных слушателей с использованием эмпирических методов обучения: наблюдения, изучения документов и результатов, тестирования, разработки дидактических материалов для экспериментальной работы в своей педагогической деятельности.

Ключевые слова: мастер; система; оптимальность; принятие; оригинальность.

\section{REFERENCES (TRANSLATED AND TRANSLITERATED)}

[1] I. P. Zhernosek, Naukovo-metodychna robota $\mathrm{V}$ zahalnoosvitnii shkoli. Kyiv, Ukraina: IZMN, 1998. $121 \mathrm{~s}$.

[2] Maister-klas v systemi metodychnoi roboty z pedahohichnymy kadramy / A. I. Postelniak. Kirovohrad, Ukraina: Vydav. KOIPPO im. Vasylia Sukhomlynskoho, 2009. $68 \mathrm{~s}$.

[3] E. V. Nechitajlova, «Tekhnologiya master-klassa v sisteme sovershenstvovaniya pedagogicheskogo masterstva uchitelya». Sovety uchitelyu. Rostov-na-Donu, Rossiya, № 11, 39 s., 2003.

[4] G. A. Russkih, «Prakticheskoe ispol'zovanie metodiki master-klassa v rabote uchitelya nauk estestvennogo cikla». Narodnoe obrazovanie», № 3, 2001.

[5] V. Andrushchenko, I. Tabachek, «Formuvannia osobystosti vchytelia v suchasnykh umovakh». Politychnyi menedzhment, № 1(10), s. 58-69, 2005.

[6] H. K. Selevko, Alternatyvni pedahohichni tekhnolohii. Moskva, Rossyia: NDI shkilnykh tekhnolohii, 2005, 224 s.

[7] O. Pometun, L. Pyrozhenko, Suchasnyi urok. Kyiv, Ukraina: A.S.K., 2005.

[8] V.V. Hryhorash, Pedahohichni rady, maister-klasy, treninhy. Kharkiv, Ukraina: Osnova, 2013. 224 s. (Seriia «Abetka kerivnyka»). 